\title{
Rafael Peres
}

\section{Influência da Ingestão de Álcool na Produção de Melatonina Pineal e suas Consequiências sobre a expressão dos receptores de melatonina e dos genes relógio no Sistema Nervoso Central}

Dissertação apresentada ao Programa de Pós-Graduação em Fisiologia e Biofísica do Instituto de Ciências Biomédicas da Universidade de São Paulo, para obtenção do Título de Mestre em Ciências (Fisiologia Humana).

São Paulo

2009 


\section{RESUMO}

Peres R. Influência da Ingestão de Álcool na Produção de Melatonina Pineal e suas Consequiências no Sistema Nervoso Central [dissertação (Mestrado em Ciências)]. São Paulo (Brasil): Instituto de Ciências Biomédicas da Universidade de São Paulo; 2009.

Já foi demonstrado que o consumo de álcool induz complicações no início do sono e na sua manutenção, mas sua influência na produção de melatonina não é clara. $\mathrm{O}$ presente trabalho mostra que ratos machos ingerindo uma solução de etanol $10 \%$ apresentam uma curva de produção de melatonina alterada, com menor produção média na noite. Isto pode ser parcialmente explicado por uma redução observada na atividade da enzima TPH e especialmente da AANAT. Também verificamos que a expressão dos genes para ambas enzimas se encontra diminuída. Os resultados mostram um impacto do álcool no início da sinalização da produção de melatonina, com alteração na expressão dos receptores de noradrenalina. Também foi observado que o tratamento modifica o padrão de expressão dos receptores de melatonina MT1 e MT2 no hipocampo, no cerebelo e no núcleo supraquiasmático. Nesta última estrutura também verificamos alterações na expressão dos genes relógio. Estas alterações em conjunto poderiam ocasionar os problemas de memória, aprendizado e sincronização circadiana descritas para pacientes alcoólatras.

Palavras chave: Melatonina; Álcool; Glândula pineal; Genes relógio. 


\begin{abstract}
Peres, R. Influence of alcoholism in the physiology of pineal gland and the consequences in the central nervous system [master thesis (Sciences)]. São Paulo (Brasil): Instituto de Ciências Biomédicas da Universidade de São Paulo; 2009.

It has been demonstrated that alcohol consumption induces complications in sleep onset and maintenance but its influence on melatonin production remains unclear. The present results show that rats receiving $10 \%$ ethanol in drinking water for 35 days display an altered melatonin daily profile, with a reduction in the nocturnal mean. This can be partially explained by the reduction in TPH and mainly in AANAT activity. In addition, mRNA expression of both enzymes was also decreased. Upstream in melatonin synthesis pathway, the results showed that noradrenergic signaling is impaired as well. Together, these results state the reasons for the observed melatonin synthesis reduction. Our results also show that alcohol intake causes an alteration in the expression of melatonin receptors MT1 and MT2 in hippocampus, cerebellum and suprachiasmatic nucleus. We have also observed an alteration in the expression of clock genes in the suprachiasmatic nucleus. These alterations are possibly causing problems to the learning, memory process and circadian synchronization.
\end{abstract}

Key words: Melatonin; Alcohol; Pineal gland; Clock genes. 


\section{INTRODUÇÃO E REVISÃO DA LITERATURA}

\section{1 Álcool}

\subsubsection{Contexto social}

Etanol, álcool etílico ou simplesmente álcool, sob forma de bebida alcoólica, é a substancia psicoativa de maior consumo mundial. O seu uso remonta há milênios: já por volta de 4000 a.C., a cerveja era produzida por fermentação na Babilônia. As técnicas de produção do vinho, descritas nos papiros egípcios, foram introduzidas na Europa em 2500 a.C. Desde então, a produção e o consumo de álcool alcançaram níveis cada vez mais crescentes, constituindo o alcoolismo um dos maiores problemas de saúde pública da atualidade (Oga, et al.,2002).

Como outras drogas, o álcool causa dependência e prejuízos ao sistema nervoso central e ao organismo. A dependência se concretiza de maneira lenta, passando despercebida, e pode demorar anos para se manifestar (Oga, et al., 2002).

O álcool é a droga mais consumida pelos brasileiros $(68,7 \%$ dos brasileiros afirmam consumi-lo com alguma freqüência), seguida pelo tabaco, maconha, cola, ansiolíticos, cocaína, xaropes e estimulantes, nesta ordem (Mendoza, 2004). Um levantamento feito pelo Cebrid (Centro Brasileiro de Informações sobre Drogas Psicotrópicas), da UNIFESP, mostrou que a substância foi responsável, em média, por 90\% das 726.429 internações psiquiátricas registradas entre 1988 e 1999. Segundo dados da Companhia de Engenharia de Tráfego, o álcool foi responsável por 76,6 mil acidentes de trânsito com vítimas ocorridas em 1995. Significam 30\% dos 255 mil acidentes registrados em todo o país no período.

O indivíduo é considerado alcoolizado se estiver com taxa a partir de 0,6 gramas de álcool por litro de sangue. A taxa de álcool no sangue varia de acordo com o peso, altura e condições físicas de cada um. Mas, em média, a pessoa não pode ultrapassar a ingestão de duas latas de cerveja ou duas doses de bebidas destiladas para estar com níveis plasmáticos suficientes para ser considerado alcoolizado (Fortes, et al., 1991).

Enquanto algumas drogas precisam de concentrações baixas para gerar seu efeito fisiológico, da ordem de miligramas, para o álcool a quantidade precisa ser bem 
maior, o que gera seu padrão de consumo característico. A quantidade de álcool nas bebidas comerciais varia de $4 \%$ a $6 \%$ (volume/volume) para cervejas, $10 \%$ a $15 \%$ para vinhos e $40 \%$ ou mais em destilados. Desta maneira, nas versões de consumo, o álcool está ajustado de maneira que a quantidade ingerida de etanol oscila por volta de $14 \mathrm{~g}$, seja numa garrafa de cerveja, numa taça de vinho ou numa dose de destilado. A quantidade de álcool que se fará presente no sangue após este consumo, entretanto, poderá variar de indivíduo para individuo de acordo com uma série de fatores, tais como frequiência de uso do álcool, sexo, massa do indivíduo e taxas metabólicas (Fortes, et al., 1991).

Cerca de $10 \%$ dos usuários ocasionais do álcool vão evoluir para o chamado quadro de pacientes alcoólatras, com detrimento físico e social. O uso crônico é acompanhado por desenvolvimento de tolerância ao etanol e dependência, ocasionando busca compulsiva pela droga (Fortes, et al., 1991).

O alcoolismo é uma doença progressiva e ocasionadora de danos cerebrais que geram déficits cognitivos. Os danos podem se dar tanto na substância branca quanto na cinzenta e estão relacionados à perda geral de produtividade mental (Kril and Halliday, 1999). O lobo frontal é particularmente sensível ao etanol, e o dano funcional é proporcional à grandeza da ingestão e duração da exposição (Pfefferbaum, et al., 1998).

\subsubsection{Absorção e metabolização do etanol}

A absorção do etanol ocorre principalmente através da mucosa do trato gastrointestinal, sendo também absorvido no trato respiratório (alvéolos) e através da pele, principalmente em crianças.

Após a ingestão, a absorção é rápida. Cerca de $20 \%$ são absorvidos no estômago e $80 \%$ no intestino delgado (duodeno, principalmente). A absorção ocorre através de difusão simples, sendo maior no início e diminuindo, posteriormente, devido ao gradiente de concentração que vai se estabelecendo: $90 \%$ ocorrem na $1^{\text {a }}$ hora e o restante nas 6 horas seguintes. $\mathrm{O}$ etanol distribui-se praticamente por todos os líquidos corpóreos, intra e extracelulares, de acordo com o conteúdo hídrico dos tecidos: no sangue, cérebro, rins, pulmões, coração, músculo estriado e fígado em ordem decrescente, respectivamente (Fortes et al., 1991). 
Após ingestão etílica e absorção, cerca de 80 a $90 \%$ do etanol sofre metabolização hepática; 2 a 10\% é excretado inalterado através dos pulmões, rins, suor e saliva e o restante é metabolizado em outros órgãos, como cérebro e músculo estriado.

A metabolização do etanol ocorre em duas etapas principais:

$-1^{\mathrm{a}}$ - transformação do etanol em acetaldeído, que se realiza principalmente no fígado.

$-2^{\mathrm{a}}$ - acetaldeído é convertido em acetato, que posteriormente é convertido em acetil-coenzima A com gasto de ATP. O acetil-CoA entra no ciclo de Krebs, transformando-se em $\mathrm{CO}_{2}$ e $\mathrm{H}_{2} \mathrm{O}$.

A catalase pode participar da metabolização do etanol (no máximo 10\%), dando conta da $\mathrm{H}_{2} \mathrm{O}_{2}$ produzida pelo hepatócito.

O consumo de etanol por longos períodos causa hipertrofia do retículo endoplasmático liso do hepatócito, com aumento de 5-10 vezes no nível de sistema microssomal oxidante de etanol, contribuindo para a tolerância metabólica observada em usuários de álcool. O etanol interfere com a gliconeogênese hepática, podendo causar hipoglicemia (Oga, et al., 2002). Os alcoólatras desenvolvem tolerância ao etanol e a outros fármacos (tolerância cruzada). Essa tolerância é devida, em parte, a adaptação do sistema nervoso central (tolerância farmacodinâmica) e à indução enzimática (tolerância metabólica). Assim, os alcoolistas, quando sóbrios, necessitam de doses maiores de fármacos que os abstêmios, para obtenção da eficácia terapêutica medicamentosa (Oga, et al., 2002).

\subsubsection{Efeitos do álcool sobre o sistema nervoso central}

O etanol é considerado um depressor do sistema nervoso central. Os efeitos sobre o SNC são proporcionais à alcoolemia. Concentrações moderadas têm efeito excitatório, gerando euforia, devido ao etanol estimular a liberação de dopamina e serotonina em áreas do cérebro relacionadas ao comportamento e ao circuito de recompensa. Com doses crescentes, observa-se o aprofundamento progressivo da depressão central. O efeito depressivo do álcool no sistema nervoso central se deve principalmente à ativação dos receptores gabaérgicos. O GABA é o mais importante neurotransmissor inibitório no cérebro. Dados de estudos eletrofisiológicos, bioquímicos e comportamentais indicam que receptores $\mathrm{GABA}_{\mathrm{A}}$ como um sítio importante de ação do álcool in vivo. O álcool vai ativar as vias neurais que irão liberar 
tal neurotransmissor, o qual reduz os disparos dos neurônios, gerando falta de coordenação motora, alteração do humor e fala indistinta (Tarter, et al., 1998). Também podem ocorrer vômitos, incontinência, hipotermia, coma e morte. Receptores de acetilcolina do tipo nicotínicos também são sítios de ação do álcool (Narahashi, et al., 1999). Tanto inibição quanto indução de ação têm sido descritos como efeitos do etanol neste receptor, dependendo da concentração da droga.

O álcool é capaz, ainda, de inibir correntes pós-sinápticas espontâneas em neurônios dopaminérgicos da substância negra. Os neurônios dopaminérgicos apresentam-se difusamente distribuídos por todo o encéfalo e estão relacionados ao sistema de recompensa, gerando procura compulsiva pela droga. (Brancucci, et al., 2004).

Por outro lado, estudos eletrofisiológicos indicam que receptores serotoninérgicos do tipo $5-\mathrm{HT}_{3}$ tem sua ação potencializada pelo etanol (Lovinger, 1999).

Os receptores excitatórios ionotrópicos de glutamato estão divididos em duas classes, os NMDA e os não-NMDA, sendo estes últimos compostos pelos subtipos ácido caínico e AMPA. Demonstra-se que o etanol inibe a função dos receptores dos tipos NMDA e ácido caínico, enquanto os receptores do tipo AMPA são resistentes à droga (Weiner, et al., 1999).

A influência do álcool sobre a concentração plasmática de noradrenalina ainda não é muito clara. Há indícios de aumento (Patkar, et al., 2004; Patkar, et al., 2003) e de ausência de variações (Ibsen, et al., 1981). Independente da concentração de noradrenalina estar alterada, demonstrou-se que há uma redução considerável do binding com os receptores do tipo alfa e do tipo beta por redução específica da afinidade. (Underwood, et al., 2004).

A administração de etanol também interfere na orientação espacial e em processos de aprendizagem e memória por sua influência na região do hipocampo (Baird, et al., 1998). O alcoolismo crônico causa perdas estruturais no hipocampo (Riley \& Walker, 1978), diminui atividade colinérgica (Melis, et al., 1996) e gera espécies reativas de oxigênio (Muresan e Eremia, 1997), processos que poderiam estar influenciando as funções acima mencionadas. O trabalho de Baydas e colaboradores (2005) mostra, ainda, que o alcoolismo crônico induz formação de espécies reativas de oxigênio e diminui a expressão de moléculas de adesão neuronal na região do 
hipocampo. Esses autores comentam, entretanto que ainda é necessário averiguar se o etanol causa morte celular de neurônios do hipocampo.

\subsubsection{Efeitos do álcool na sinalização celular}

A visão clássica de ação do etanol na fisiologia celular é de que ele simplesmente desestabilizaria os lipídios de membrana. Entretanto, há fortes indícios de que sua ação se concentraria mais precisamente nas proteínas, alterando, entre outros fatores, a excitabilidade dos neurônios.

O efeito do etanol sobre proteínas quinases ainda não é bem claro. Alguns pesquisadores afirmam que o álcool seria capaz de inibir a ação da proteína quinase $C$ (PKC), enquanto outros não verificaram efeito algum (Stubbs e Slater, 1999). Talvez isso se deva a ações diferentes do etanol sobre cada uma das diferentes isoformas da proteína quinase $\mathrm{C}$. A translocação das proteínas quinase A e $\mathrm{C}$ do citoplasma para o núcleo é afetada pelo álcool (Constantinescu, et al., 1999; Yao, et al., 2008). Cascatas de transdução de sinal intracelular que envolvam MAP e fatores tirosina quinase também são afetadas pelo etanol (Valenzuela e Harris, 1997).

Já foi descrita queda na atividade da adenilato ciclase em pacientes alcoólatras (Parsian, et al., 1996) e até mesmo em descendentes de pacientes alcoólatras.

\subsection{Glândula Pineal e Melatonina}

O órgão pineal origina-se, embriologicamente, de uma evaginação dorsal do teto do III ventrículo, e no cérebro adulto, constitui, junto com os núcleos habenulares, a maior parte do epitálamo (Ekström e Meissl, 2003). Acompanhando sua evolução, vemos que em lampreias, peixes cartilaginosos e ósseos, anfíbios, tartarugas, lagartos e pássaros, o órgão pineal é diretamente fotossensível. Nos mamíferos, entretanto, o órgão perde sua capacidade fotorreceptiva e passa a estar sob o controle do sistema nervoso central notadamente do simpático cervical. Assim, as influências do ciclo de iluminação ambiental passam a se dar de forma indireta, através de projeções da retina para estruturas diencefálicas e destas para os neurônios pré-ganglionares, que podem, através da inervação simpática periférica, atingir a glândula pineal (Vollrath, 1981; Korf, 2000, Cipolla-Neto, et al., 1995). Assim, vemos que o tipo celular majoritário do corpo pineal, 
o pinealócito, teve uma evolução conjunta com a irradiação dos vertebrados, com uma perda gradual da função fotorreceptora e um aumento da função neuroendócrina, presente em todos os vertebrados (Collin, 1969).

O controle da função hormonal da glândula é assim feito pelo ciclo dianoite. Tal controle é bastante refinado, com o seu hormônio, a melatonina, sendo produzido, na maior parte das espécies durante a noite. Dessa forma, a melatonina circulante tem, também, seu perfil plasmático variável de acordo com as noites mais longas ou mais curtas típicas das diversas estações do ano (Reiter, 1993). Fica claro assim a função fisiológica da glândula pineal: sinalizar para o meio interno pela presença e ausência diária da melatonina na circulação e nos diversos líquidos corpóreos, se é noite ou dia no meio exterior e, através da duração do seu perfil secretório noturno, qual é a estação do ano (Cipolla-Neto e Afeche, 1999).

Existem outros locais de síntese da melatonina, tais como retina e sistema gastrintestinal, entretanto acredita-se que a melatonina sintetizada nestas regiões tem maior importância na modulação de fenômenos locais (Arendt, 1995).

A melatonina ( $N$-acetil 5-metoxitriptamina) é uma indolamina, de peso molecular 232,3 kdaltons. O processo de produção de melatonina se inicia quando o aminoácido triptofano é transformado em 5-hidroxitriptofano (5HTP), pela enzima triptofano 5-hidroxilase. Após isso, uma descarboxilase de aminoácidos aromáticos inespecífica transforma o 5HTP em serotonina.

O transporte de triptofano no sistema nervoso central se dá através de um sistema de transporte de aminoácidos neutros, e, assim, um sistema semelhante a esse poderia estar carregando o triptofano para dentro dos pinealócitos (Sugden, et al., 1989). A enzima não parece estar saturada com relação ao seu substrato uma vez que a administração de triptofano produz um aumento dos níveis de serotonina na pineal (Young Anderson, 1982).

Na glândula pineal do rato, a enzima TPH apresenta um ritmo circadiano de atividade, com valores mais elevados no período noturno, fazendo com que a síntese de 5-hidroxitriptofano concentre-se durante a noite. Esse aumento da atividade de cerca de 2 vezes durante a noite deve-se tanto à sua síntese aumentada, pela indução de transcrição gênica e síntese protéica, como à ativação da enzima por fosforilação (Besançon, et al., 1996; Shibuya, et al., 1978). Tanto o ritmo do RNA mensageiro da TPH, como o ritmo da atividade da enzima são induzidos por estimulação noradrenérgica, através da via do AMPc e proteína quinase A (PKA). A PKA, pela 
fosforilação da proteína CREB promove a transcrição da enzima TPH ( Ehret, et al., 1991; Shein \& Wurtman, 1971). A fosforilação da TPH pode ser feita pela PKA, pela quinase dependente de cálcio e calmodulina (CaMK) e pela PKC (Ehret, et al., 1989, 1991; Johansen, et al., 1995, 1996; Simonneaux e Ribelayga, 2003)

A regulação da atividade da TPH também é feita através de sua associação com a proteína 14-3-3. A TPH fosforilada pela CaMK, PKC ou pela PKA liga-se à proteína 14-3-3, aumentando, assim, a sua atividade e impedindo a sua desfosforilação (Ichimura, et al., 1987, 1995; Banik, et al.,1997; Klein , et al.,2003).

A serotonina secretada tem um papel na própria pineal, atuando através dos seus receptores do tipo 5- $\mathrm{HT}_{2}$, e aumentando a síntese de melatonina induzida por noradrenalina (Aloyo e Walker, 1988; Olcese e Munker, 1994; Sugden, 1990). A serotonina é $\mathrm{N}$-acetilada pela aril-alquil- $\mathrm{N}$-acetiltransferase (AANAT) produzindo $\mathrm{N}$ acetil serotonina (NAS). A AANAT é a enzima passo-limitante da síntese de melatonina, pois ela apresenta um aumento de 100 vezes na sua atividade no período noturno, deslocando o metabolismo da serotonina para a produção de $N$ acetilserotonina.

A ativação noturna da via neural de projeção periférica para a glândula pineal induz a liberação de noradrenalina nas proximidades dos pinealócitos, os quais apresentam receptores $\alpha$ e $\beta$-adrenérgicos. Da interação com os receptores $\beta$ (subtipo $\beta_{1}$ ) há a indução do aumento do AMPc intracelular através da ativação de uma proteína $G$ estimulatória (Gs) e da enzima adenilato ciclase. A ativação dos receptores $\alpha$ (subtipo $\alpha_{1 B}$ ) ativa uma proteína $\mathrm{Gq}$ ligada à estimulação da fosfolipase $\mathrm{C}$, gerando $\mathrm{IP}_{3} \mathrm{e}$ diacilglicerol. $\mathrm{O} \mathrm{IP}_{3}$, atuando em seus receptores no retículo endoplasmático, induz a liberação do cálcio desses estoques, tendo como conseqüência um aumento do cálcio intracitoplasmático. $\mathrm{O}$ aumento do cálcio induzido por noradrenalina caracteriza-se por um pico seguido de um platô. A rápida elevação do cálcio deve-se à liberação do retículo (Schaad, et al., 1995) e o platô que se segue parece dever-se à entrada de cálcio pelos canais da membrana plasmática responsáveis pela reposição dos estoques intracelulares (Gomperts, et al., 2002).

$\mathrm{O}$ cálcio e o diacilglicerol ativam a proteína quinase $\mathrm{C}(\mathrm{PKC})$, a qual potencia o aumento do AMPc já induzido pela estimulação $\beta$-adrenérgica. Este efeito pode ocorrer pela fosforilação da adenilato ciclase ou da proteína Gs (Klein, et al., 1983; Sugden, 1989; Sugden, et al., 1985, 1986, 1987). O cálcio tem um papel potenciador da síntese do AMPc intracelular também por atuar através do complexo 
cálcio/calmodulina na ativação da adenilato ciclase, que na glândula pineal foi caracterizada como do tipo 1 (Anholt, 1994; Tazavara, et al.,1996).

No rato, o AMPc ativa a proteína quinase A do tipo II (PKA) (Maronde, et al., 1999), a qual fosforila um fator de transcrição, a proteína CREB (“cAMP response element binding"), que, assim fosforilada, promove a ativação da transcrição e da tradução gênicas da enzima aril-alquilamina $\mathrm{N}$-acetiltransferase. A presença da CREB fosforilada é muito importante também para a manutenção da atividade da AA-NAT, pois, quando a CREB é desfosforilada, se tem uma rápida queda na atividade da enzima (Klein, et al., 1996; Koch, et al., 2003; Roseboom e Klein, 1995; Tamotsu, et al., 1995). A estimulação adrenérgica induz também a síntese de fatores de transcrição negativos na glândula pineal, sendo um dos mais importantes o ICER ("inducible cAMP early repressor"), que tem um papel inibitório mais tardio da transcrição do gene da AANAT. O RNA mensageiro do ICER exibe um ritmo circadiano na pineal do rato, com um pico na segunda metade da noite, precedendo o declínio da síntese de melatonina. Além do ICER, o AMPc estimula a síntese de outros fatores de transcrição negativos como do Fra-2 ("Fos-related antigen-2") e JunB que também poderiam estar promovendo a queda circadiana da atividade da AANAT (Baler e Klein, 1995; Spesser, et al., 2000).

A AANAT é uma enzima instável e a manutenção de sua atividade depende de muitos fatores. Quando cessa a estimulação simpática, ou se administram antagonistas adrenérgicos ou se submete o animal a uma fotoestimulação no meio da noite, a atividade da AANAT cai com uma meia vida de aproximadamente $3 \mathrm{~min}$ (Cipolla-Neto e Afeche, 2007; Deguchi e Axelrod, 1972; Klein e Weller, 1972; Klein, et al., 1978; Parfitt, et al., 1976).

A estabilização da atividade desta enzima deve-se à presença do AMPc em níveis elevados durante todo o período noturno. A ativação da PKA pelo AMPc, leva à fosforilação da enzima em dois sítios específicos localizados no N-terminal e no Cterminal. Quando a AANAT está fosforilada ocorre a sua ligação com a proteína 14-3-3 zeta, ligação essa que se dá através do sítio da enzima fosforilado pela PKA, formando, então, um complexo AANAT-14-3-3. Essa associação impede que a AANAT seja metabolizada por um mecanismo de proteólise proteassomal. A proteína 14-3-3 zeta também promove um aumento da atividade da AANAT, pois na ausência da 14-3-3 a sua atividade apresenta-se reduzida (Ganguly, et al., 2001). 
O passo final da produção da melatonina ocorre quando a enzima hidroxindol-O-metiltransferase (HIOMT, também chamada de acetilserotonina metiltransferase- Asmt) transforma a NAS em melatonina. A atividade da HIOMT no período noturno apresenta um aumento de 1.5 vezes, enquanto o seu RNA mensageiro tem um aumento de 2 vezes (Simonneaux e Ribelayga, 2003; Ribelayga, et al., 1999). A regulação da atividade da HIOMT, diferentemente das enzimas anteriores, ocorre à longo prazo. Trabalhos com animais expostos à luz constante ou que tiveram removidos os seus gânglios cervicais superiores verificaram uma redução na atividade da HIOMT, mas os níveis basais dos RNAs da enzima não estavam alterados (Sugden, 1989).

O neurotransmissor glutamato tem uma ação inibitória sobre a síntese de melatonina. Ele interage com receptores metabotrópicos do grupo II, mGluR3, presente nos pinealócitos. Esses receptores estão acoplados a uma proteína Gi, fazendo com que diminua o AMPc, e, conseqüentemente, a síntese de melatonina seja diminuída (Yamada, et al., 1998).

Após sua produção, a melatonina é liberada nos espaços perivasculares da glândula, de onde se difunde para a circulação. Na circulação sanguínea a melatonina é transportada ligada a proteínas, em especial a albumina.

$\mathrm{Na}$ circulação a meia vida da melatonina é de cerca de 20 minutos. Isso decorre da metabolização periférica da melatonina, concentrada especialmente no fígado (aproximadamente $90 \%$ da melatonina circulante). A melatonina é convertida em 6-hidroximelatonina, se conjuga em especial com sulfatos ou com glucoronídeos e é excretada na urina. No sistema nervoso central e na própria glândula pineal a melatonina tem um processo de degradação diferente, decorrente de interação com outras moléculas (em especial radicais livres) podendo ser transformada em quinuraminas como o AFMK e o AMK (Tan, et al., 2007).

As características químicas da molécula da melatonina, pela presença dos grupamentos metoxi, no carbono 5, e do grupamento acil, ligado ao nitrogênio do grupo amina, são de anfifilicidade. Ou seja, ela tem a propriedade de difundir-se adequadamente tanto em meios hidrofílicos quanto lipofílicos. Dessa forma, a melatonina, uma vez produzida na glândula pineal, é imediatamente secretada e pode ser encontrada em todos os compartimentos do organismo. Além disso, os carbonos 2 e 3 do anel pirrólico, possuem uma alta capacidade de doar elétrons. Isso confere a melatonina uma alta capacidade antioxidante. 
Além da ação direta, a melatonina também pode agir nas células por receptores específicos. Existem tanto receptores de membrana quanto nucleares. Nos mamíferos estão bem caracterizados três tipos de receptores de membrana. Os receptores de alta afinidade, $\mathrm{MT}_{1}$ e $\mathrm{MT}_{2}$, pertencem à superfamília dos receptores ligados à proteína $\mathrm{G}$. Em particular, ligam-se à proteína $\mathrm{G}_{\mathrm{i}}$, promovendo, ambos, uma redução na produção do AMPc. No caso do $M_{1}$, além de ligar-se à $G_{i}$, o receptor tem afinidade pela proteína $\mathrm{G}_{\mathrm{q} / 11}$ o que lhe confere a característica de dependendo das circunstâncias, potencializar a produção de diacilglicerol e $\mathrm{IP}_{3}$, podendo aumentar a concentração intracelular de cálcio e atividade da PKC. Por outro lado, está demonstrado em vários sistemas, que a melatonina, mediada pelo receptor $\mathrm{MT}_{1}$, pode ativar correntes retificadoras de potássio, diminuindo as despolarizações celulares, resultando numa redução do influxo de cálcio através dos canais de cálcio dependentes de voltagem. Os mecanismos mobilizados pela $\mathrm{G}_{\mathrm{i}}$, quando o receptor $\mathrm{MT}_{2}$ é ativado podem resultar numa redução do GMPc, também. Além disso, sabe-se, ainda, que a mobilização de proteínas $G_{i}$ implica, em muitos sistemas, como no caso dos receptores de melatonina, na mobilização de dois mecanismos de transdução intracelular: um dependente do componente $\alpha$ (inibição da adenilato ciclase) e outro dependente do componente $\beta \gamma$, resultando na ativação da fosfolipase $\mathrm{C}$.

Os receptores de alta afinidade estão distribuídos por todo o organismo desde o sistema nervoso central, onde está presente em várias estruturas, até a periferia do organismo, em muitos órgãos e tecidos.

O terceiro tipo de receptor de membrana para melatonina existente em mamíferos é o $\mathrm{MT}_{3}$, um receptor cuja estrutura molecular é muito parecida com uma enzima, a quinona redutase, e cujas ações não estão completamente esclarecidas. $\mathrm{O}$ receptor nuclear conhecido para a melatonina é um dos receptores órfãos da família dos receptores de ácido retinóico do tipo RZR/ROR $\alpha$. Alguns dos efeitos atribuídos a essa interação são a expressão da enzima lipo-oxigenase, a expressão das enzimas antioxidantes e a síntese de interleucina2.

A melatonina desempenha diversas funções nos seres vivos, além de sinalização circadiana e o papel de antioxidante. Ela age mobilizando mecanismos reparadores do DNA (Burkhardt, et al., 2001), regula diretamente a ação de diversas enzimas, e possui também ação intra-mitocondrial, regulando o metabolismo oxidativo 
e o transporte de elétrons (Reiter, et al., 2004). Por essa e outras ações, a melatonina é capaz de regular o processo de apoptose celular (Mayo, et al., 1998).

\subsubsection{Influência do álcool na fisiologia da glândula pineal}

Em alcoólatras, distúrbios na produção de melatonina ainda não são inteiramente conhecidos. Kühlwein e colaboradores (2003) compararam a quantidade de melatonina no plasma sanguíneo de humanos alcoólatras e controles e verificaram um atraso para alcançar o pico de concentração, além de valores menores nas dosagens da

primeira metade da noite nos usuários de álcool. Entretanto, um trabalho bastante recente de Danel e Touitou (2006) mostrou que uma intoxicação com 265g de etanol distribuídos ao longo do dia não causa qualquer mudança na melatonina plasmática de humanos.

A produção de melatonina em indivíduos alcoólatras logo em seguida a retirada do álcool também tem dados controvertidos, com trabalhos citando aumento (Fonzi, et al., 1994) ou diminuição (Schmitz, et al., 1996, Kühlwein, et al., 2003) na concentração de melatonina plasmática.

Em ratos, no entanto, demonstrou-se, também, que uma intoxicação com etanol por um tempo de um a quatro dias leva a uma menor concentração de melatonina na glândula pineal, com um aumento na concentração de serotonina (Moss, et al., 1986).

Nenhum dos trabalhos presentes na literatura que indicam mudanças na concentração de melatonina investigou a existência de danos à glândula pineal como morte celular ou danos a seu DNA. Também não há qualquer relato na literatura sobre alteração na expressão das enzimas responsáveis pela via de produção de melatonina.

\subsection{O núcleo supraquiasmático e a expressão rítmica circadiana dos genes do relógio}

Desde a descoberta dos núcleos supraquiasmáticos (NSQ) hipotalâmicos como um local primordial do marcapasso circadiano em mamíferos, muitos autores tentaram desvendar os mecanismos da ritmicidade endógena.

A luz, agindo através da via retino-hipotalâmica, é um importante sincronizador da atividade rítmica circadiana gerada pelo NSQ. Demonstrou-se a capacidade de diversos outros agentes ambientais agirem como sincronizadores do 
oscilador circadiano: atividade motora, escuro, disponibilidade de alimentos, etc. No entanto, um grande avanço na compreensão da organização rítmica circadiana deu-se com a compreensão do papel sincronizador interno exercido pela melatonina.

Os núcleos supraquiasmáticos se localizam na região hipotalâmica ventral anterior, acolados lateralmente ao terceiro ventrículo e circundados, parcialmente, pelo quiasma óptico. Em ratos, projeções neuronais retinianas são primariamente direcionadas à região ventrolateral (ou porção central) dos núcleos supraquiasmáticos. A parte dorsomedial (ou externa) não recebe aferências retinianas diretas, recebendo aferências corticais e subcorticais de estruturas não envolvidas com a visão. A porção ventrolateral, além das conexões retinianas diretas, via trato retino-hipotalâmico, recebe projeções retinianas indiretas provindas do folheto intergeniculado do tálamo, via trato genículo-hipotalâmico, além de projeções da rafe mesencefálica. Os neurônios da porção ventrolateral do NSQ contêm como neurotransmissores, principalmente, o polipeptídio intestinal vasoativo (VIP) e o GABA, enquanto que neurônios da porção dorsolateral possuem vasopressina (AVP) e GABA, além de serem marcados pela calretinina.

A descoberta dos genes do relógio e o princípio geral de sua oscilação vêm estimulando várias pesquisas sobre o assunto (Okamura, et al., 2002, Roenneberg e Mellow, 2002).

Em 1984 foi isolado em Drosophila melanogaster, o primeiro gene do relógio, o period, e nesta espécie foi descoberto que a transcrição deste gene era induzida quando o nível das proteínas PERIOD (ou seja, proteínas que são produzidas pela transcrição e tradução do próprio gene) apresentava-se reduzido. Dez anos depois da identificação do period, o segundo gene descoberto foi o timeless, com um mecanismo proposto de autoregulação por um feedback negativo. $\mathrm{O}$ gene frequency foi descoberto em Neurospora. Estes achados fixaram o conceito de que a oscilação circadiana nas funções celular poderia ser causada por um processo rítmico de transcrição/tradução dos genes do relógio, cujo período se aproximaria das $24 \mathrm{~h}$. Até este momento ainda não se sabia da existência dos genes relógio em mamíferos, apenas havia sido realizado experimentos na tentativa de provar a existência de um relógio central, localizado nos núcleos supraquiasmáticos.

Em 1994 o gene clock foi nomeado a partir de um estudo mutagênico em camundongos usando-se N-etil-N-Nitrosourea, e criou-se um animal com um gene mutante, onde o ritmo circadiano da atividade locomotora havia sido abolido após duas 
semanas de alojamento em escuro constante. Estes achados sugeriram que os ritmos circadianos são determinados a nível gênico nos mamíferos.

Nos anos de 1997 e 1998 vários grupos de pesquisadores isolaram genes homólogos ao gene period de Drosofila em mamíferos. O mPerl, mPer2 e mPer3, os quais continham domínios PAS (period, arnt and sim), o qual é um domínio importante para interações proteína-proteína e localização do domínio citoplasmático que ajuda a manter proteínas no citoplasma. A clonagem simultânea do gene clock do relógio de ratos revelou a codificação da proteína PAS/bHLH ("basis helix loop helix"). Heterodímeros desta proteína ligam-se a E-box da região promotora do mPerl. Estes resultados sugeriram que o mecanismo de um autofeedback negativo presente na Drosofila estava também presente nos mamíferos. Associadamente ao fato que camundongos com deficiência em ambos os genes mPerl e mPer2 não expressavam ritmos circadianos, estes estudos sugeriram que ambos os genes são genes oscilatórios indispensáveis para geração de ritmos circadianos em camundongos.

Para provar definitivamente que mPerl e mPer2 possuem a capacidade de gerar oscilações, foi investigada a introdução dos genes mPerl e mPer2 de ratos em Drosofila com gene mutante arrítmico $\mathrm{Per}^{01}$ para avaliar se a introdução causaria a recuperação funcional. Em avaliação comportamental mostraram que mPerl e mPer2 dirigidos pelo timeless (Drosofila), restauraram os ritmos em Perl, e os ritmos restaurados por mPer2 foram mais intensos e diferiram na periodicidade daqueles restaurados por mPerl, mostrando-se assim que ambos atuam como componentes funcionais do relógio.

As transcrições dos genes mPerl e mPer2 são estimuladas pela ligação de heterodímeros formados pelas proteínas CLOCK e BMAL1 (bHLH-PAS) na região Ebox do gene mPerl e possivelmente a promotores do gene mPer2, ativando-se assim a transcrição gênica, originando os mRNAs dos genes de mPerl e mPer2 os quais são traduzidos nas proteínas mPER1 e mPER2 no citoplasma. Quando a concentração destas proteínas aumenta, agrupam-se formando um complexo negativador (do qual fazem parte, também, as proteínas mCRY1, mCRY2, mPER3 e mTIM), que suprime a transcrição dos genes mPerl e mPer2 por se ligarem aos fatores positivos (CLOCK e BMAL1), bloqueando-os. Dessa forma, proteínas nucleares como mCRY1, mCRY2 e mTIM ligando-se com mPER1, mPER2 e mPER3, podem formar um complexo negativador estável, que está envolvido no termino da transcrição dos genes mPerl e mPer2 fechando a alça de retroalimentação (Gillette e Mitchell, 2002). 
Os monômeros protéicos mPER1 e mPER2, são fosforilados por uma caseína quinase $(\mathrm{CKI} \varepsilon)$, e nessa forma fosforilada são rapidamente degradados. Assim o mecanismo que determina a concentração de proteínas no relógio é a sua fosforilação, sendo que, a fosforilação impedindo o acúmulo dessas proteínas, impede a formação de complexos negativadores que suprimiriam as transcrições dos genes mPerl e mPer2.

Há evidências crescentes que proteínas do relógio são reguladas dinamicamente. Proteínas mPERs são frágeis quando não se dimerizam com proteínas mCRY, fortes supressores transcricionais do mPerl, e podem ser ubiqüitinizadas quando as proteínas do mPER estão ausentes. Assim o complexo negativador é estável para suprimir a transcrição dos genes mPerl e mPer2 (Gillette e Mitchell, 2002).

A maquinaria de oscilação endógena envolve interações positivas e negativas, transcricionais e pós traducionais com alças de retroalimentação envolvendo os genes do relógio Per1, 2, 3, Clock, Bmall, Cryl e Cry2 (Gillette e Mitchell, 2002, Stehle, et al.,2003). O sincronizador dos NSQs é o ciclo de claro/escuro. Outros fatores também possuem a atividade cronobiótica e sincronizante sobre os NSQs, especialmente a melatonina. Melatonina aplicada em culturas de fatias dos NSQs, agindo via receptores MT1, muda imediatamente a fase de atividade elétrica neuronal e , via receptores MT2 sincroniza a ritmicidade circadiana da atividade elétrica neuronal. Já, in vivo, injeções diárias de melatonina, em animais em livre-curso, sincronizam os ritmos circadianos de atividade/repouso. Nestas circunstâncias experimentais, a melatonina afetou a expressão de mRNAs dos genes do relógio a partir da segunda noite circadiana. Estes resultados sugerem que o efeito modificador de fase imediato da melatonina nos NSQs depende mais de mecanismos pós-traducionais do que transcricionais. 


\section{CONCLUSÃO}

Em resumo, os resultados mostram que a ingestão de álcool provoca:

1- Uma redução na produção de melatonina, com um atraso para alcançar o pico de produção, alterando o ritmo de produção, sem contudo prejudicar a integridade nem a viabilidade das células da glândula.

2- Uma alteração na curva de expressão diária de duas das enzimas responsáveis pela síntese de melatonina (TPH, AA-NAT), sem afetar a expressão da proteína 14-3-3;

3- Uma redução de 35\% no pico de atividade da TPH e de $70 \%$ no pico de atividade da AA-NAT, na glândula pineal, sem afetar a atividade da HIOMT;

4- Uma alteração considerável da curva diária da expressão gênica dos receptores alfa 1 e beta 1 adrenérgico na glândula pineal;

5- Uma alteração na expressão diária dos receptores MT1 e MT2 no cerebelo, no núcleo supraquiasmático e no hipocampo.

6- Uma alteração na curva de expressão diária dos genes relógio analisados no núcleo supraquiasmático (Cry 1, Cry2, Per 1, Per 2, Clock e Bmal 1). 


\section{REFERÊNCIAS BIBLIOGRÁFICAS ${ }^{1}$}

Akashi M, Takumi T. The orphan nuclear receptor ROR-alpha regulates circadian transcription of the mammalian core-clock Bmal1. Nat Struct Mol Biol. 2005; May;12(5):441-8. Epub Apr 10.

Aloyo VJ, Walker, RF. Alpha-Adrenergic Control of Serotonin Release From Rat Pineal Glands. Neuroendocrinology. 1988; 48: 61-66.

Anholt RRH. Signal integration in the nervous system: adenylate cyclases as molecular coincidence detectors. TINS. 1994; 17 (1): 37-41.

Arendt J. Melatonin and the Mammalian Pineal Gland. London: Chapman \& Hill; 1995.

Baird TJ, Vanecek SA, Briscoe RJ. Moderate, longterm, alcohol consumption potentiates normal, age-related of recent Alcohol. Clin Exp Res. 1998; 22:628-636.

Baler R, Klein DC. Circadian expression of transcription factor Fra-2 in the rat pineal gland. J Biol Chem. 1995; 270: 27319-25.

Baltatu O, Afeche SC, José Dos Santos SH, Campos LA, Barbosa R, Michelini LC, Bader M, Cipolla-Neto J. Locally synthesized angiotensin modulates pineal melatonin generation. J Neurochem. 1992; Jan;80(2):328-34.

Banik U, Wang GA, Wagner PD, Kaufman S. Interaction of phosphorylated tryptophan hydroxylase with 14-3-3 proteins. J Biol Chem. 1997; 272: 26219-25.

Baydas G, Abdullah Y, Mehmet T. Comparison of the impact of melatonin on chronic ethanol-induced learning and memory impairment between young and aged rats. $\mathbf{J}$ Pineal Res. 2005; 79: 1-7.

Baydas G, Ozer M, Yasar A, Tuzcu M, Koz ST. Melatonin improves learning and memory performances impaired by hyperhomocysteinemia in rats. Brain Res. 2005 Jun 7;1046(1-2):187-94.

\footnotetext{
${ }^{1}$ De acordo com:

International Committee of Medical Journal Editors. Uniform requirements for manuscripts submitted to Biomedical Journal: sample references. Available from: http://www.icmje.org [2007 May 22].
} 
Besançon R, Simonneaux V, Jouvet A, Belin MF, Fèvre-Montange M. Nycthmeral expression of tryptophan hydroxylase mRNAs in the rat pineal gland. Mol Brain Res. 1996; 40: 136-8.

Borjigin J, Wang MM, Snyder SH. Diurnal variation in mRNA encoding serotonin Nacetyltransferase in pineal gland. Nature. 1995; 378: 783-785.

Brancucci A, Berretta N, Mercuri NB, Francesconi W. Gamma-hydroxybutyrate and ethanol depress spontaneous excitatory postsynaptic currents in dopaminergic neurons of the substantia nigra. Brain Research. 2004. 997, 62-66.

Brower KJ, Aldrich MS, Hall JM. Polysomnographic and subjective sleep predictors of alcoholic relapse. Alcohol Clin Exp Res. 1998; 22:1864-1871.

Brzezinski A. Melatonin in humans. NEJM. 1997; 336:186-195.

Burkhardt S, Reiter RJ, Tan DX, Hardeland R, Cabrera J, Karbownik M. DNA Oxidatively Damaged By Chromium(III) And $\mathrm{H}(2) \mathrm{O}(2)$ Is Protected By The Antioxidants Melatonin, N(1)-Acetyl-N(2)-Formyl-5-Methoxykynuramine, Resveratrol And Uric Acid. Int J Biochem Cell Biol. 2001 Aug; 33(8):775-83.

Carlberg C, Wiesenberg I. The orphan receptors family RZR/ROR, melatonin and 5lipoxygenase: An unexpected relationship. J Pineal. 1995; 18: 171-178.

Chou TC, Scammell TE, Gooley JJ, Gaus SE, Saper CB, Lu J. Critical role of dorsomedial hypothalamic nucleus in a wide range of behavioral circadian rhythms. $\mathrm{J}$ Neurosci. 2003; Nov 19;23(33):10691-702

Cipolla-Neto J, Skorupa AL, Ribeiro-Barbosa ER, Bartol I, Mota SR, Afeche SC, Delagrange P, Guardiola-Lemaitre B, Canteras NS. The role of the retrochiasmatic area in the control of pineal metabolism. Neuroendocrinology. 1999; 69(2):97-104.

Cipolla-Neto J, Afeche SC. Glândula Pineal. In: Aires MM, editor. Fisiologia. Rio De Janeiro: Guanabara-Koogan; 1999. p. 805-11.

Cipolla-Neto J, Bartol I, Seraphim PM, Afeche SM, Scialfa JH, Peraçoli AM. The effects of lesions of the thalamic intergeniculate leaflet on the pineal metabolism. Brain Res. 1995 Sep 11;691(1-2):133-41. 
Collin JP. Contribution A 'L'e'Tude De L'organe Pine'Al. De L'e'Piphyse Sensorielle A La Glande Pine'Ale: Modalite'S De Transformation Et Implications Fonctionelles. Ann Stn Biol. Besse-en-Chandesse. 1969; Suppl. 1:1-359.

Collin JP. Differentiation And Regression Of The Cells Of The Sensory Line In The Epiphysis Cerebri. In: Wolstenholme GEW, Knight J, editors. The Pineal Gland. London: J. A. Churchill; 1971. p. 79-125.

Constantinescu A, Diamond I, Gordon AS. Ethanol-induced translocation of cAMPdependent protein kinase to the nucleus. Mechanism and functional consequences. $\mathrm{J}$ Biol Chem. 1999; Sep 17;274(38):26985-91.

Danel T, Touitou Y. Alcohol Consumption Does Not Affect Melatonin Circadian Synchronization In Healthy Men. Alcohol Alcohol. 2006 May 5.

Deguchi T, Axelrod J. Sensitive Assay For Serotonin N-Acetyltransferase Activity In Rat Pineal. Anal Biochem.1972; 50: 176-9.

Drummond SP, Gillin JC, Smith TL, Demodena A. The sleep of abstinent pure primary alcoholic patients: Natural course and relationship to relapse. Alcohol Clin Exp Res. 1998; 22:1796-1802.

Dubocovich ML. Melatonin receptors: role on sleep and circadian rhythm regulation. Sleep Med. 2007 Dec;8 Suppl 3:34-42.

Ehret M, Cash CD, Hamon M, Maitre M. Formal demonstration of the phosphorilation of rat brain tryptophan hydroxylase by $\mathrm{Ca}^{2+} /$ calmodulin-dependent protein kinase. $\mathrm{J}$ Neurochem. 1989; 52:1886-91.

Ehret M, Pevet P, Maitre M. Tryptophan hydroxylase synthesis is induced by 3,5'cyclic adenosine monophosphate during circadian rhythm in the rat pineal gland. $\mathbf{J}$ Neurochem. 1991; 57:1516-21.

Ekstrom P, Meissl H. Evolution Of Photosensory Pineal Organs In New Light: The Fate Of Neuroendocrine Photoreceptors. Philos Trans R Soc Lond B Biol Sci. 2003; 358(1438):1679-700.

El-Sherif Y, Tesoriero J, Hogan MV, Wieraszko A. Melatonin regulates neuronal plasticity in the hippocampus. J Neurosci Res. 2003 May 15;72(4):454-60. 
Esparza JL, Gómez M, Rosa-Nogués M, Paternain JL, Mallol J, Domingo JL. Melatonin reduces oxidative stress and increases gene expression in the cerebral cortex and cerebellum of aluminum-exposed rats. J Pineal Res. 2005 Sep;39(2):129-36.

Fonzi S, Solinas GP, Costelli P, Parodi C, Murialdo G, Bo P, Albergati A, Montalbetti L, Savoldi F, Polleri A. Melatonin and cortisol circadian secretion during ethanol withdrawal in chronic alcoholics. Chronobiologia. 1994 Jan-Jun;21(1-2):109-12.

Fortes JRA, Cardo WN. Alcoolismo - diagnóstico e tratamento. São Paulo: Sarvier Editora de Livros Médicos Ltda; 1991.

Fuller PM, Gooley JJ, Saper CB. Neurobiology of the sleep-wake cycle: sleep architecture, circadian regulation, and regulatory feedback. J Biol Rhythms. 2006 Dec;21(6):482-93.

Fraser S, Cowen P, Franklin M, Franey C, Arendt J. Direct radioimunoassay for melatonin in plasma. Clin Chem. 1983; 29:396-7.

Ganguly S, Gastel JA, Weller JL, Schwartz C, Jaffe H, Namboodiri MAA, Coon SL, Hickman AB, Rollag M, Obsil T, Beauverger P, Ferry G., Boutin JA, Klein DC. Role of a pineal cAMP-operated arylalkylamine N-acetyltransferase/ 14-3-3-binding switch in melatonin synthesis. Proc. Natl Acad Sci USA. 2001; 98:8083-8.

Garcia RA, Afeche SC, Scialfa JH, do Amaral FG, dos Santos SH, Lima FB, Young ME,Cipolla-Neto J. Insulin modulates norepinephrine-mediated melatonin synthesis in cultured rat pineal gland. Life Sci. 2008 Jan 2;82(1-2):108-14. Epub 2007 Nov 1.

Gastel JA, Roseboom PH, Rinaldi PA, Weller JL, Klein DC. Melatonin production: proteasomal proteolysis in serotonin $\mathrm{N}$-acetyltransferase regulation. Science. $1998 \mathrm{Feb}$ 27;279(5355):1358-60.

Gillette MU, Mitchell JW. Signaling in the supracvhiasmatic nucleus: selectively responsive and integrative. Cell Tissue Res. 2002 Jul;309(1):99-107. Epub 2002 Jun 6. Review.

Gillin JC, Smith TL, Irwin M, Butters N, Demodena A, Schuckit M. Increased pressure for rapid eye movement sleep at time of hospital admission predicts relapse in nondepressed patients with primary alcoholism at 3-month follow-up. Arch Gen Psychiatry. 1994 Mar;51(3):189-97. 
Gomperts BD, Kramer IM, Tatham PER. Signal transduction. San Diego (Ca): Academic Press; 2002. p. 145-187.

Ibsen H, Christensen NJ, Rasmussen S, Hollnagel H, Damkjaer Nielsen M, Giese J. The influence of chronic high alcohol intake on blood pressure, plasma noradrenaline concentration and plasma renin concentration. Clin Sci (Lond). 1981 Dec;61 Suppl $7: 377 \mathrm{~s}-379 \mathrm{~s}$.

Ichimura T, Isobe T, Okuyama T, Yamauchi T, Fujisawa H. Brain 14-3-3 protein is an activator protein that activates tryptophan 5-monooxygenase in the presence of $\mathrm{Ca} 2+$, calmodulin-dependent protein kinase II. FEBS Lett. 1987 Jul 13;219(1):79-82.

Ichimura T, Uchiyama J, Kunihiro O, Ito M, Horigome T, Omata S, Shinkai F, Kaji H, Isobe $\mathrm{T}$. Identification of the site of interaction of the 14-3-3 protein with phosphorylated tryptophan hydroxylase. J Biol Chem. 1995 Dec 1;270(48):28515-8.

Johansen PA, Jennings I, Cotton RG, Kuhn DM. Tryptophan hydroxylase is phosphorylated by protein kinase A. J Neurochem. 1995 Aug;65(2):882-8.

Johansen PA, Jennings I, Cotton RG, Kuhn DM. Phosphorylation and activation of tryptophan hydroxylase by exogenous protein kinase A. J Neurochem. 1996 Feb;66(2):817-23.

Klein DC, Weller JL. Rapid Light-Induced Decrease In Pineal Serotonin NAcetyltransferase Activity. Science. 1972 Aug 11;177(48):532-3.

Klein DC, Buda MJ, Kapoor CL, Krishna G. Pineal Serotonin N-Acetyltransferase Activity: Abrupt Decrease In Adenosine 3,5'-Monophosphate May Be Signal For “Turnoff”. Science. 1978 Jan 20;199(4326):309-11.

Klein DC, Sugden D, Weller JL. Postsynaptic $\alpha$-adrenergic receptors potentiate the $\beta$ adrenergic stimulation of pineal serotonin $\mathrm{N}$-acetyltransferase. Proc Natl Acad Sci U S A. 1983 Jan;80(2):599-603.

Klein DC, Roseboom PH, Coon SL. New light is shining on the melatonin rhythm enzyme. The first poscloning view Trends Endocrinol Metab. 1996 Apr;7(3):106-12.

Klein DC, Ganguly S, Coon SL, Shi Q, Gaildrat P, Morin F, Weller JL, Obsil T, Hickman A, Dyda F. 14-3-3 proteins in pineal photoneuroendocrine transduction: how many roles? J Neuroendocrinol. 2003 Apr;15(4):370-7. Review. 
Koch M, Mauhin V, Stehle JH, Schomerus C, Korf HW. Desphosphorylation of pCREB by protein serine/threonine phosphatase is involved in inactivation of NAT gene transcription in rat pineal gland. J Neurochem. 2003 Apr;85(1):170-9.

Korf HW. Evolution of Melatonin-Producing Pinealocytes. In: Olcese J, editor. Melatonin After Four Decades. New York: Kluwer/Plenum; 2000. p. 17-29.

Kril JJ, Halliday GM. Brain shrinkage in alcoholics: a decade on and what have we learned? Prog Neurobiol. 1999 Jul;58(4):381-7. Review.

Kühlwein E, Hauger RL, Irwin MR. Abnormal Nocturnal Melatonin Secretion and Disordered Sleep in Abstinent Alcoholics. Biol Psychiatry. 2003 Dec 15;54(12):143743.

Lerchl A, Nonaka KO, Stokkan KA, Reiter RJ. Rapid alterations in nocturnal pineal serotonin in mice and rats exposed to weak intermittent magnetic fields. Biochem Biophys Res Commun. 1990 May 31;169(1):102-8.

Liu C, Weaver DR, Jin X, Shearman LP, Pieschl RL, Gribkoff VK, Reppert SM. Molecular dissection of two distinct actions of melatonin on the suprachiasmatic circadian clock. Neuron. 1997 Jul;19(1):91-102.

Lu J, Zhang YH, Chou TC, Gaus SE, Elmquist JK, Shiromani P, Saper CB. Contrasting effects of ibotenate lesions of the paraventricular nucleus and subparaventricular zone on sleep-wake cycle and temperature regulation. J Neurosci. 2001 Jul 1;21(13):4864-74.

Lovinger DM. 5-HT3 receptors and the neural actions of alcohols: an increasingly exciting opic. Neurochem Int. 1999 Aug;35(2):125-30. Review.

Manda K, Ueno M, Anzai K. Melatonin mitigates oxidative damage and apoptosis in mouse cerebellum induced by high-LET 56Fe particle irradiation. J Pineal Res. 2008 Mar;44(2):189-96.

Maronde E, Wicht H, Taskén K, Genieser HG, Dehghani F, Olcese J, Korf HW. CREB phosphorylation and melatonin biosynthesis in the rat pineal: involvement of cyclic AMP dependent protein kinase Type II. J Pineal Res. 1999 Oct;27(3):170-82. 
Mayo JC, Sainz RM, Uria H, Antolin I, Esteban MM, Rodriguez C. Melatonin Prevents Apoptosis Induced By 6-Hydroxydopamine In Neuronal Cells: Implications For Parkinson Disease. J Pineal Res. 1998 Apr;24(3):179-92.

McCarthy JJ, Andrews JL, McDearmon EL, Campbell KS, Barber BK, Miller BH, Walker JR, Hogenesch JB, Takahashi JS, Esser KA. Identification of the circadian transcriptome in adult mouse skeletal muscle. Physiol Genomics. 2007 Sep 19;31(1):8695. Epub 2007 Jun 5.

Mendoza AZ. O uso do álcool na adolescência, uma expressão de masculinidade [tese (doutorado)]. Ribeirão Preto (São Paulo): Escola de Enfermagem de Ribeirão Preto da Universidade de São Paulo; 2004.

Melis F, Stancampiano R, Imperato A, Carta G, Fadda F. Chronic ethanol consumption in rats: correlation between memory performance and hippocampal acetylcholine release in vivo. Neuroscience. 1996 Sep;74(1):155-9.

Moss HB, Tamarkin L, Majchrowicz E, Martin PR, Linnoila M. Pineal function during ethanol intoxication, dependence, and withdrawal. Life Sci. 1986 Dec 8;39(23):220914.

Mureşan C, Eremia I. Ethanol stimulates the formation of free oxygen radicals in the brain of newborn rats. Rom J Morphol Embryol. 1997 Jul-Dec;43(3-4):113-7.

Narahashi T, Aistrup GL, Marszalec W, Nagata K. Neuronal nicotinic acetylcholine receptors: a new target site of ethanol. Neurochem Int. 1999 Aug;35(2):131-41. Review.

Oga S, Basile AC, Carvalho, MF. Guia Zanini-Oga de interações medicamentosas: base teórica das interações. São Paulo: Atheneu; 2002.

Okamura H, Yamaguchi S, Yagita K. Molecular machinery of the circadian clock in mammals. Cell Tissue Res. 2002 Jul;309(1):47-56. Epub 2002 Jun 11. Review.

Olcese J, Münker M. Extracellular Serotonin Promotes Melatonin Release From Cultured Rat Pinealocytes: Evidence For An $\mathrm{S}_{2}$-Type Receptor-Mediated Autocrine Feedback. Brain Res. 1994 Apr 18;643(1-2):150-4.

Pandi-Perumal SR, Srinivasan V, Poeggeler B, Hardeland R, Cardinali DP. Drug Insight: the use of melatonergic agonists for the treatment of insomnia-focus on ramelteon. Nat Clin Pract Neurol. 2007 Apr;3(4):221-8. Review. 
Parfitt A, Weller JL, Klein DC. Beta Adrenergic-Blockers Decrease Adrenergically Stimulated N-Acetyltransferase Activity In Pineal Glands In Organ Culture. Neuropharmacology. 1976 Jun;15(6):353-8.

Parsian A, Todd RD, Cloninger CR, Hoffman PL, Ovchinnikova L, Ikeda H, Tabakoff B. Platelet adenylyl cyclase activity in alcoholics and subtypes of alcoholics. Alcohol Clin Exp Res. 1996 Jun;20(4):745-51.

Patkar AA, Gopalakrishnan R, Naik PC, Murray HW, Vergare MJ, Marsden CA. Changes in plasma noradrenaline and serotonin levels and craving during alcohol withdrawal. Alcohol Alcohol. 2003 May-Jun;38(3):224-31.

Patkar AA, Marsden CA, Naik PC, Kendall DA, Gopalakrishnan R, Vergare MJ, Weinstein SP. Differences in Peripheral Noradrenergic Function among Actively Drinking and Abstinent Alcohol-dependent Individuals. Am J Addict. 2004 MayJun;13(3):225-35.

Pfefferbaum A, Sullivan EV, Rosenbloom MJ, Mathalon DH, Lim KO. A controlled study of cortical gray matter and ventricular changes in alcoholic men over a 5-year interval. Arch Gen Psychiatry. 1998 Oct;55(10):905-12.

Raghavendra V, Kulkarni SK. Possible antioxidant mechanism in melatonin reversal of aging and chronic ethanol-induced amnesia in plus-maze and passive avoidance memory tasks. Free Radic Biol Med. 2001 Mar 15;30(6):595-602.

Reiter RJ. The Melatonin Rhythm: Both A Clock And A Calendar. Experientia. 1993 Aug 15;49(8):654-64. Review.

Reiter RJ, Tan DX, Gitto E, Sainz RM, Mayo JC, Leon J, Manchester LC, Vijayalaxmi, Kilic E, Kilic U. Pharmacological Utility Of Melatonin In Reducing Oxidative Cellular And Molecular Damage. Pol J Pharmacol. 2004 Mar-Apr;56(2):159-70. Review.

Ribelayga C, Gauer F, Calgari C, Pevet P, Simonneaux V. Photoneural Regulation Of Rat Pineal Hydroxyindole-O-Methyltransferase (HIOMT) Messenger Ribonucleic Acid Expression: An Analysis Of Its Complex Relationship With HIOMT Activity. Endocrinology. 1999 Mar;140(3):1375-84.

Riley JN, Walker DW. Morphological alterations in hippocampusafter long-term alcohol consumption in mice. Science. 1978 Aug 18;201(4356):646-8. 
Roenneberg T, Merrow M. "What watch?...such much!"Complexity and evolution of circadian clocks. Cell Tissue Res. 2002 Jul;309(1):3-9. Epub 2002 May 18. Review.

Roseboom PH, Klein DC. Norepinephrine stimulation of pineal cyclic AMP response element-binding protein phosphorylation: primary role of a $\beta$-adrenergic receptor/cyclic AMP mechanism. Mol Pharmacol. 1995 Mar;47(3):439-49.

Roseboom PH, Coon SL, Baler R, McCune SK, Weller JL, Klein DC. Melatonin synthesis: analysis of the more than 150-fold nocturnal increase in serotonin $\mathrm{N}$ acetyltransferase messenger ribonucleic acid in the rat pineal gland. Endocrinology. 1996 Jul;137(7):3033-45.

Rupp TL, Acebo C, Carskadon MA. Evening Alcohol Suppresses Salivary Melatonin in Young Adults. Chronobiol Int. 2007;24(3):463-70.

Schaad NC, Vanecek J, Rodriguez IR, Klein DC, Holtzclaw L, Russell JT. Vasoactive intestinal peptide elevates pinealocyte intracellular calcium concentrations by enhancing influx: evidence for involvement of a cyclic GMP-dependent mechanism. Mol Pharmacol. 1995 May;47(5):923-33.

Shein HM, Wurtman RJ. Stimulation of $\left[{ }^{14} \mathrm{C}\right]$ tryptophan 5-hydroxylation by norepinephrine and dibutyryl adenosine 3,5, monophosphate in rat pineal organ cultures. Life Sci I. 1971 Aug 15;10(16):935-40.

Shibuya H, Toru M, Watanabe S. A circadian rhythm of tryptophan hydroxylase in rat pineals. Brain Res. 1977 Dec 16;138(2):364-8.

Simonneaux V, Ribelayga C. Generation Of The Melatonin Endocrine Message In Mammals: A Review Of The Complex Regulation Of Melatonin Synthesis By Norepinephrine, Peptides, And Other Pineal Transmitters. Pharmacol Rev. 2003 Jun;55(2):325-95. Review.

Sisodia R, Kumari S, Verma RK, Bhatia AL. Prophylactic role of melatonin against radiation induced damage in mouse cerebellum with special reference to Purkinje cells. J Radiol Prot. 2006 Jun;26(2):227-34. Epub 2006 May 26.

Spessert R, Rapp M, Jastrow H, Karabul N, Blum F, Vollrath L. A differential role of CREB phosphorylation in cAMP-inducible gene expression in the rat pineal. Brain Res. 2000 May 12;864(2):270-80. 
Stehle JH, von Gall C, Korf HW. Melatonin: a clock-output, a clock-input. J Neuroendocrinol. 2003 Apr;15(4):383-9. Review.

Stubbs CD, Slater SJ. Ethanol and protein kinase C. Alcohol Clin Exp Res. 1999 Sep;23(9):1552-60. Review.

Sugden D, Vanecek J, Klein DC, Thomas TP, Anderson WB. Activation of protein kinase $\mathrm{C}$ potentiates isoprenaline-induced cyclic AMP accumulation in rat pinealocytes. Nature. 1985 Mar 28-Apr 3;314(6009):359-61.

Sugden AL, Sugden D, Klein DC. Essential role of calcium influx in the adrenergic regulation of cAMP and cGMP in rat pinealocytes. J Biol Chem. 1986 Sep $5 ; 261(25): 11608-12$.

Sugden LA, Sugden D, Klein DC. $\alpha_{1}$-Adrenoceptor activation elevates cytosolic calcium in rat pinealocytes by increasing net influx. J Biol Chem. 1987 Jan $15 ; 262(2): 741-5$.

Sugden D. Melatonin biosynthesis in the mammalian pineal gland. Experientia. 1989 Oct 15;45(10):922-32.

Sugden D. 5-Hydroxytryptamine Amplifies Beta-Adrenergic Stimulation Of $\mathrm{N}$ Acetyltransferase Activity In Rat Pinealocytes. J Neurochem. 1990 Nov;55(5):1655-8.

Tamotsu S, Schomerus C, Stehle JH, Roseboom PH, Korf HW. Norepinephrine-induced phosphorylation of the transcription factor CREB in isolated rat pinealocytes: an immunocytochemical study. Cell Tissue Res. 1995 Nov;282(2):219-26.

Tan DX, Manchester LC, Terron MP, Flores LJ, Reiter RJ. One molecule, many derivatives: a never-ending interaction of melatonin with reactive oxygen and nitrogen species? J Pineal Res. 2007 Jan;42(1):28-42. Review.

Tarter RE, Ammerman Rt, Ott PJ. Handbook of substance abuse. Neurobehavioral pharmacology. New York; London: Plenun Press; 1998.

Tzavara ET, Pouille Y, Defer N, Hanoune J. Diurnal variation of the adenylyl cyclase type 1 in the rat pineal gland. Proc Natl Acad Sci U S A. 1996 Oct 1;93(20):11208-12. 
Underwood MD, Mann JJ, Arango V. Serotonergic and Noradrenergic Neurobiology of Alcoholic Suicide. Alcohol Clin Exp Res. 2004 May;28(5 Suppl):57S-69S.

Valenzuela CF, Harris RA. Alcohol: Neurobilogy. In: Lowinson JH, Ruiz P, Millman RB, Langrod JB, editors. Substance Abuse: Acomprehensive Textbook. Baltimore: Willians \& Wilkins; 1997. p. 119-142.

Vollrath L. The Pineal Organ. In: Oksche A, Vollrath L. Handbuch Der Mikroskopischen Anatomie Des Menschen. Vol 6/7. Berlin; Heidelberg; New York: Springer; 1981.

Webley GE, Mehl H, Willey KP. Validation of a sensitive direct assay for melatonin for investigation of circadian rhythms in different species. $J$ Endocrinol. 1985 Sep;106(3):387-94.

Weiner JL, Dunwiddie TV, Valenzuela CF. Ethanol inhibition of synaptically evoked kainate responses in rat hippocampal CA3 pyramidal neurons Mol Pharmacol. 1999 Jul;56(1):85-90.

Yamada H, Yatsushiro S, Ishio S, Hayashi M, Nishi T, Yamamoto A, Futai M, Yamaguchi A, Moriyama Y. Metabotropic glutamate receptors negatively regulate melatonin synthesis in rat pinealocytes. J Neurosci. 1998 Mar 15;18(6):2056-62. Review.

Yao L, Fan P, Jiang Z, Gordon A, Mochly-Rosen D, Diamond I. Dopamine and Ethanol Cause Translocation of \{epsilon\}PKC Associated with \{epsilon $\}$ RACK: Crosstalk Between PKA and PKC Signaling Pathways. Mol Pharmacol. 2008 Apr;73(4):1105-12. Epub 2008 Jan 17.

Young SN, Anderson GM. Factors influencing melatonin, 5 hydroxytryptophol, 5hydroxyindolacetic acid, 5-hydroxytryptamine and tryptophan in rat pineal glands. Neuroendocrinology. 1982 Dec;35(6):464-8. 